\title{
VIDEO LECTURES AS A MEAN OF ACHIEVING BETTER RESULTS IN INTRODUCTORY PROGRAMMING COURSES
}

\author{
Mario Konecki ${ }^{1}$ \\ ${ }^{1}$ University of Zagreb, Faculty of Organization and Informatics, Pavlinska 2, Varaždin, Croatia
}

\begin{abstract}
Introductory programming courses have been dealing with underachievement and unexpectedly low results for years. Many visualization tools have been developed in order to try to increase the overall quality of knowledge and acquired programming skills in introductory programming courses. The situation has however not changed much. This paper proposes an approach which includes video lectures as a mean of providing students with a more interesting way of learning and with increased level of flexibility in their learning of programming concepts. An attempt to use specially developed video lectures in introductory programming course is presented in this paper along with the discussion about the effectiveness of this kind of approach.
\end{abstract}

Keywords: programming courses, problems, video lectures, students

\section{INTRODUCTION}

Introductory programming courses have been experiencing many difficulties with students not being able to understand programming concepts and structures in sufficient amount. The students' test results are frequently unexpectedly low which shows that students are indeed unable to follow the course lectures. This results in students loosing track of presented programming concepts and consequently in difficulties to perform well in solving of given practical programming tasks. Very often there are reports about computer science students who don't do well at their programming jobs in programming industry. One thing that is stated and accepted by many authors is that programming is considered as hard to learn [10;16; 17]. Programming concepts and structures are simply not intuitive and are as such hard to perceive by students which are not used to this new way of thinking that is required in order to write proper computer programs. Because of this fact it can be said that it is necessary to find means that will make programming concepts clearer to students and easier to learn. Hawi states that there are 10 causes that are responsible for occurring problems in programming education. These causes include learning strategy, lack of study, lack of practice, subject difficulty, lack of effort, appropriate teaching method, exam anxiety, cheating, lack of time, and unfair treatment [8]. Learning strategy is the most commonly mentioned cause of problems in programming education which suggests that changes should be made to this aspect in the first place in order to achieve better results in introductory programming courses.

Different visualization tools have been developed and used with various results in order to try to make programming concepts clearer to students [14]. In order to achieve better results in introductory programming courses several goals need to be achieved. There is a need to motivate students in greater amount, to make them able to have insight into lecture materials because of the need to clarify or repeat certain elements of these lectures and there is also a need to make presented tasks more interesting and of more practical nature which should make students more eager to do a greater number of tasks which is important aspect of students' programming skills development process. Video lectures are one of the possible means that can be used in introductory programming courses in order to achieve better results. Video lectures can be used in two different ways. Either they are used as a part of classroom lectures to clarify certain programming concepts or as a standalone online video materials. Each of two mentioned approaches has its own advantages. In the case of video lectures that are used in the classroom there is an advantage of teachers presence and peers' support and in the case of online video materials the advantage is that these materials are available for students to view them at any time and place as well as that the students are able to repeat certain parts or the whole lecture more than one time. This promotes individual work and greater level of understanding. One aspect that is also of great importance is the video materials design that results in better or worse effect of created lectures.

\section{CLASSIC APPROACH AND VIDEO LECTURES}

Classic approach in introductory programming courses includes theoretical knowledge presentations that are presented to students during lectures. Students are presented with mostly theoretical knowledge and some examples. Since programming is a skill [13] opposite to pure knowledge-based courses it requires somewhat different approach which should incorporate a larger amount of practical work and examples. Doing their homework tasks is one of the most important factors in students' successful acquiring of programming skills. Opposite from classic approach students show tendency towards simultaneous learning of theory and practice [9] which is more engaging and makes students more actively included in their own 
educational process. Practical examples have proven to be more interesting for students compared to classic lectures that frequently result in decreased attention and focus [21]. Traditional lectures however include interpersonal communication and peers' as well as lecturer's encouragement [23]. This aspect is important because interaction has been recognized for years as an important part of educational process [2]. When talking about problems of classic approach in introductory programming there are several aspects that can be pointed out [10]:

- Programming should never be taught before the second year of any course

- $\quad$ The language used should be chosen for pedagogic suitability and not because it is popular in industry

- $\quad$ Programming should be taught by those who can teach programming and not those who can program

- Programming courses should be designed to be flexible to allow different students to learn in different ways

- $\quad$ There should be no summative (continuous) assessment to ease pressure on students

- Departments should acknowledge that programming is difficult and supply adequate support to students

As stated programming is difficult and it should be made more flexible and appropriate for students' pace and style of learning. Video lectures enable better explanation and presentation of the overall process of converting input to output in given programming examples which promotes better understanding of programs' dynamics [3]. Video lectures also enable students to go through the lectures at home which leaves more space for doing a larger number of examples and exercises. This kind of approach promotes constructivism and active learning [24] since students are more included in the formation of their own knowledge as they form a larger part of their knowledge at home using video lectures and doing presented examples and given tasks. This kind of approach is also consistent with industry and its constant demand for programming experts who have a greater skills regarding practical programming tasks. There is a need for change in programming courses in a way that includes more examples, projects and tasks [6]. Nevertheless, the proper knowledge and overview of algorithmic way of thinking $[11 ; 12]$ which includes problem-solving skills and programming principles have to be adopted prior to doing any real exercises. Since classic lectures and materials have been described as passive and in many cases ineffective [6] more interesting and engaging approach which includes video lectures should increase the overall results quality of introductory programming courses.

Video lectures have been proven as a promising mean of achieving better results in education in the past, before modern video recording technology. TVI (Tutored Videotape Instruction) model that uses videotapes has proven to be better in many aspects compared to classic lectures [7]. Various archives of lectures is something that becomes more and more popular in many educational systems because of lesser cost, greater reusability and flexibility for students regarding their time and location [1].Video lectures are gaining their popularity especially after some well-known institutions (for example Princeton and MIT) started with their usage [18].Various research reports on improved programming courses results as a consequence of using video lectures that students are able to watch before actual lectures which are then used for questions and exercises $[15 ; 6 ; 5]$. Video lectures that have been put online and can be viewed on demand have several advantages. For example one of the facts is that to learn how to program requires a lot of practice and a cumulative acquiring of knowledge. Online video lectures enable students to catch up with missed or misunderstood programming concepts which is very hard to achieve in classic lecture approach [20].Putting video lectures online results in greater flexibility regarding time, pace and location of their usage [22].Research reports on students who use distance learning to have better results than students who attend classic lectures but also that the students who use distance learning finish their courses in lesser percentage than students who attend classic lectures [4]. Another advantage of video lectures is that they can be beneficial for various types of students with different types of disabilities since they combine video and audio channel. The conducted research has shown that video lectures can be beneficial for visually impaired students as well as for students with other disadvantages [19].

\section{INTRODUCTORY PROGRAMMING AND} VIDEO LECTURES

In order to make introductory programming courses more interesting and closer to students a number of video lectures have been created. When designing these lectures an idea was to make them different and appealing to students so it was decided to make them in improvised video studio with more sophisticated video equipment. The background of lectures was set to be a stage with darker and less intensive colors that will not distract the viewer from concentrating on the lectures themselves. Rather than just capturing the screen content and adding a face of lecturer it was decided to capture the whole person who is then shown in the lower right corner of the video lecture in order to make video lectures as close to real lectures as possible because of lecturer's presence on these lectures just as the lecturer is present in the real classroom. One of important details in this process was the choice of lecturer's clothes colors. These colors have been chosen in such a way to be similar to background stage colors again with the purpose to make the lecturer visible but not popping out and distracting viewers form the lecture slides. Finally, in the center of attention is the slide canvas which position on a stage reminds on a movie canvas and shows the lecture slides that have white background in order to pop and capture the viewer's attention. The design concept of created video lectures is shown in Fig. 1. 


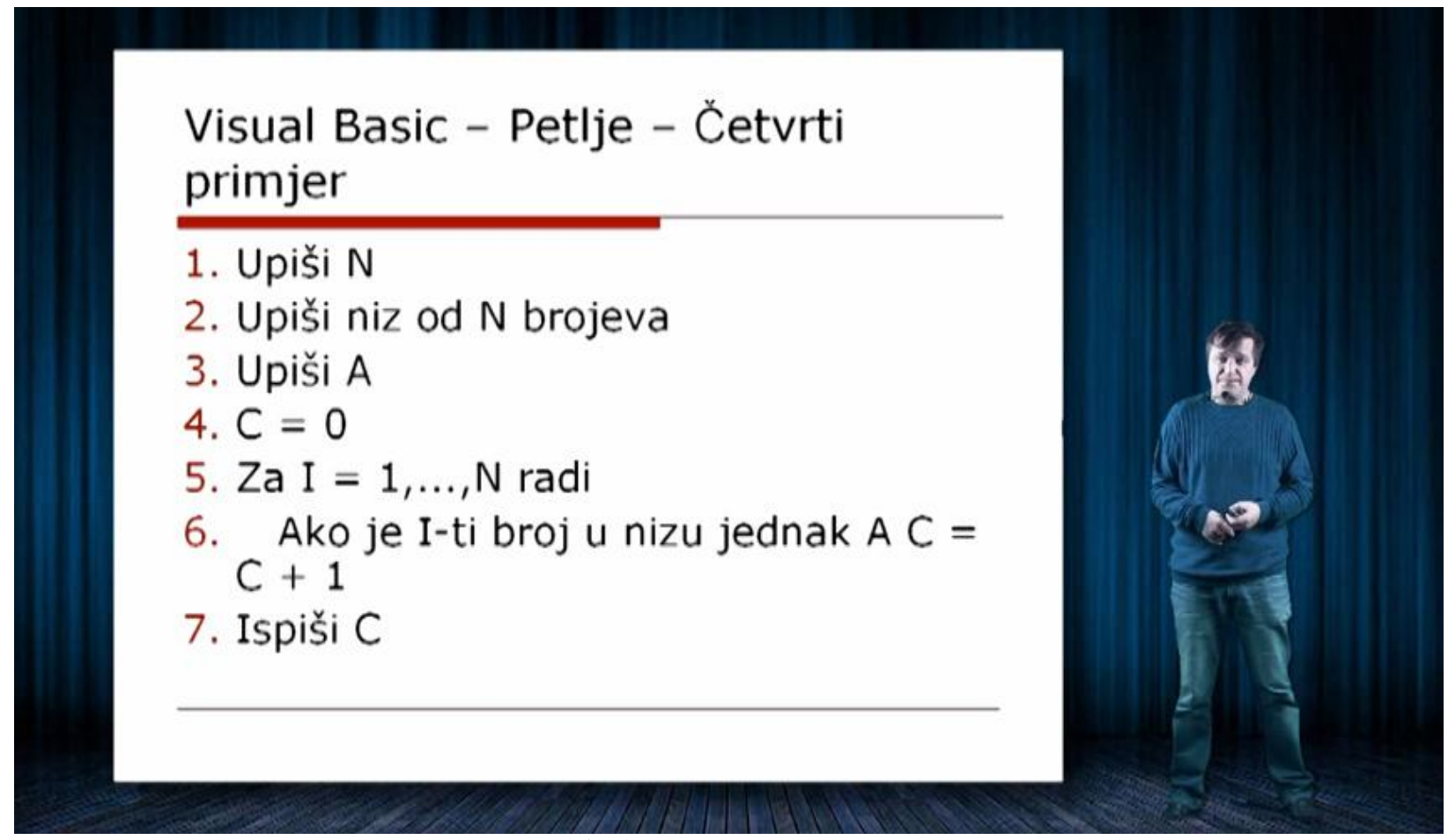

Fig 1 Video lecture design

Aside from creating video lectures the videos that include step-by-step demonstration of given programming examples were also recorded. These videos included voice and full screen capture of programming environment and steps of given programming examples development process. It was already mentioned that video lectures can actually be appropriate for visually impaired and students with other disabilities so the future work in this area will include adding textual description of performed steps in lower part of videos in order to add additional presentation media as additional accessibility measure. All created videos have been made available online as part of course's learning platform. In this way students were able to go through the lectures when they wanted, they were able to go back and forth in order to go through elements that were not clear to them at first and students were also able to pause lectures when they felt their concentration altered and that they are not focused which is not possible during actual classroom lectures.

Along with video materials corresponding presentations in PowerPoint format along with programming examples and homework tasks were also made available online. Since purely online lectures have disadvantages of lecturer not being present and not being able to moderate the lectures, ask question and give support to students some key parts of lectures were repeated in the classroom in order to promote mentioned aspects. The rest of the lecture time in the classroom was spent on presentation of programming examples and student's presentations of their homework tasks as well as on discussion about former and current lesson content. In this way students also maintain a feeling of being part of the group which promotes student's willingness to work and finish their course. This aspect is lacking in purely online courses since students are not supported by their peers with whom they have no actual contact.

The created video lectures were used in introductory programming course where students were divided into 2 groups. One group was using video materials and all developed features that were available on course's learning platform and one group was using classic lecture approach. Overall number of students that participated in the research was 81 with 48 students using video materials and 33 students using classic lecture approach. In order to test the potential difference between two groups of students the homework tasks were graded and all students were given a final test. Students were also given a short questionnaire in order to state their attitude towards given video lectures. The results of students' homework and test both gave better results among students that were using given video lectures. The homework tasks consisted of 3 independent tasks and final test consisted of 5 tasks and 3 theoretical questions. The average percentage of correct answers among the group of students that was using video materials was $82 \%$ for their homework tasks and $65 \%$ for their final test. The group of students that was using classic lecture approach had $70 \%$ correct answers on their homework tasks and 54\% correct answers on their final test. All students also had a chance to state their attitude towards given visual lectures and the conclusion was that video lectures made programming more interesting, easier to understand and learn as well as more suited for students' desired pace of learning. Students that were using video lectures have also been motivated in greater amount compared to students that were using classic approach. 
Students have also been interviewed to find about their experience with provided video lectures in more detail. Most of students have reported that they have used video lectures about 2 times a week and that they did not finish the particular lecture at once but rather in several parts which indicates that students indeed prefer greater flexibility regarding their time of learning because they get tired or overwhelmed by certain parts of lecture so it is beneficial to them to take a short break in order to restore their concentration which enables them to understand the rest of the lecture in a greater amount. Students also reported that they have been going back and forth in lecture sometimes in order to clarify some elements. The comments given by students suggest that dividing the lectures into shorter parts which would reduce the particular lecture length and enable easier navigation through the course lectures programme could prove as beneficial to students.

\section{CONCLUSION}

Introductory programming courses experience persistent problems in teaching students about different programming concepts and students are frequently not able to solve even the most basic tasks. Programming is abstract and not intuitive to students which makes its concepts hard to perceive and adopt for most of students. Various visualization tools have been developed and proposed as a mean of making different programming concepts more understandable for students. These tools have shown various results in practice. Video lectures are one of possible means that can be used to help students in clarification of programming concepts which brings greater flexibility to students regarding the time and place of learning and also a more interesting way of learning. This kind of approach leaves more time for teachers to spent on presentation of practical examples which are the most important part of programming education because of the nature of programming which is a skill and as every other skill it requires a lot of practice. An approach which includes a series of video lectures which have been develop for usage in introductory programming course has been presented in this paper. These video lectures have been designed in such a way to provide a more focused, more flexible and more interesting way of learning which also leaves more time for practical examples. Created video lectures have been used as a part of introductory programming course and have shown to be an efficient mean that enables improvements in homework and test results of introductory programming students. Video lectures have also been reported as something that creates a positive attitude among students because of greater flexibility in their learning of programming which shows that this kind of approach can indeed be beneficial to students. Further development of additional video lectures and testing of impact of these lectures on overall student population will be a part of future work.

\section{REFERENCES}

[1] Anderson, R., Dickey, M., \& Perkins, H. (2001). Experiences with tutored video instruction for introductory programming courses. ACM SIGCSE Bulletin, 33(1), 347-351.

[2] Anderson, T. (2003). Getting the mix right again: An updated and theoretical rationale for interaction. The International Review of Research in Open and Distance Learning, 4(2).

[3] Bennedsen, J., \&Caspersen, M. E. (2005). Revealing the programming process. ACM SIGCSE Bulletin, 37(1), 186-190.

[4] Dutton, J., Dutton, M., \& Perry, J. (2001). Do online students perform as well as lecture students?. Journal of Engineering Education, 90(1), 131-136.

[5] Day, J., \& Foley, J. (2006). Evaluating web lectures: A case study from HCI. In Proceedings of Conference on Human Factors in Computing Systems (pp. 195-200). ACM, New York, NY, USA.

[6] Foertsch, J., Moses, G., Strikwerda, J., \&Litzkow, M. (2002). Reversing the Lecture/Homework Paradigm Using eTEACH® Web- based Streaming Video Software. Journal of Engineering Education, 91(3), 267-274.

[7] Gibbons, J. F., Kincheloe, W. R., \& Down, K. S. (1977). Tutored videotape instruction: a new use ofelectronics media in education. Science, 195,11391146.

[8] Hawi, N. (2010). Causal attributions of success and failure made by undergraduate students in an introductory-level computer programming course. Computers \& Education, 54(4), 1127-1136.

[9] Hu, M. (2004). Teaching novices programming with core language and dynamic visualization. In Proceedings of the 17th NACCQ(pp. 94-103). Christchurch, New Zealand.

[10] Jenkins, T. (2002). On the difficulty of learning to program. In Proceedings of the 3rd Annual Conference of the LTSN Centre for Information and Computer Sciences (pp. 53-58).Loughborough, UK.

[11] Konecki, M., \&Petrlić, M. (2014). Main problems of programming novices and the right course of action. InT.Hunjak, S.Lovrenčić,\& I.Tomičić (Eds.),Proceedings of the 25th Central European Conference on Information and Intelligent Systems (pp. 116-123). FOI, Varaždin, Croatia.

[12] Konecki, M. \&Mrkela, V. (2014). Algorithmic thinking and animated interactive presentation of sorting algorithms in education of students. In V. Rajkovič, M. Bernik, \& U. Rajkovič (Eds.),Proceedings of the 17th International Multiconference Information Society Education in Information Society (pp. 105-112), IJS, Ljubljana, Slovenia.

[13] Konecki, M. (2014). Problems in programming education and means of their improvement, DAAAM International Scientific Book 2014, in press.

[14] Konecki, M. \&Mrkela, V. (2014). Students' acceptance of animated interactive presentation of sorting algorithms. In F. Novak, B. Blažica, C.Bohak,\& L.Čehovin (Eds.), Proceedings of the 17 th International Multiconference Information Society - Human-Computer Interaction in 
Information Society (pp. 18-21), IJS, Ljubljana, Slovenia.

[15] Lage, M. J., Platt, G. J., \&Treglia, M. (2000). Inverting the classroom: A gateway to creating an inclusive learning environment. The Journal of Economic Education, 31(1), 30-43.

[16] Peng, W. (2010). Practice and experience in the application of problem-based learning in computer programming course. In L. Yuting (Ed.), Proceedings of the International Conference on Educational and Information Technology (ICEIT) (pp. 1:170-172). IEEE.

[17] Robins, A., Rountree, J., \&Rountree, N. (2003). Learning and teaching programming: A review and discussion. Computer Science Education, 13(2), 137172.

[18] Ronchetti, M. (2010). Using video lectures to make teaching more interactive. International Journal of Emerging Technologies in Learning (iJET), 5(2), 4548.

[19] Ronchetti, M. (2010). Assessing a new methodology for using video-lectures. World Conference on Educational Multimedia, Hypermedia and Telecommunications, 2010(1), 2127-2135.

[20] Smith, G., \&Fidge, C. (2008). On the efficacy of prerecorded lectures for teaching introductory programming. InS. Hamilton, \&M. Hamilton,Proceedings of the tenth conference on Australasian computing education (pp. 129-136), 78, Australian Computer Society, Inc..

[21] Tan, P. H., Ting, C. Y., \& Ling, S. W. (2009). Learning difficulties in programming courses: undergraduates' perspective and perception. InB. Werner (Ed.),Proceedings of the IEEE International Conference on Computer Technology and Development (pp. 1:42-46). IEEE.

[22] Wallace, D. R., \&Mutooni, P. (1997). A Comparative Evaluation of World Wide Web- Based and Classroom Teaching. Journal of Engineering Education, 86(3), 211-219.

[23] Ward, M., \& Newlands, D. (1998). Use of the Web in undergraduate teaching. Computers \& Education, 31(2), 171-184.

[24] Wulf, T. (2005). Constructivist approaches for teaching computer programming. In Proceedings of the 6th conference on Information technology education (pp. 245-248). ACM, New York, NY, USA. 